\title{
Epidemiological comparison of injuries in school and senior club rugby
}

Department of Public Health Sciences, University of Edinburgh, Edinburgh, United Kingdom

A J Lee, research associate

W M Garraway, professor

Correspondence to: Miss A J Lee, Department of Public Health Sciences, University of Edinburgh, Medical School, Teviot Place, Edinburgh EH8 9AG, Scotland.

Accepted for publication 14 March 1996

\begin{abstract}
Objective-To determine the frequency, nature, circumstances, and outcome of schoolboy rugby injuries and to compare these injuries with those occurring in senior rugby clubs.
\end{abstract}

Methods-The study was a prospective cohort study, conducted on $1705(98 \%)$ of 1736 eligible players from nine Edinburgh schools and 1169 (96\%) of 1216 eligible players from all 26 senior Scottish Rugby Union clubs (South District) who provided personal details before the 19931994 rugby season. Adult linkpersons were appointed to notify the circumstances of all injury episodes occurring in matches or in rugby related training.

Results-154 school players (9\%) experienced 210 separate injuries in 186 injury episodes, $\mathbf{8 0 \%}$ of which arose in matches. The prevalence rate of schoolboy match injuries was 86.8 (95\% confidence interval 73.4 to 100.2 ) per 1000 player-seasons. Senior club match injury prevalence was much higher at 367.0 (339.4 to 394.6) per 1000 player-seasons. Club players had a higher rate of match injury than schoolboys for all injury types. One third of schoolboy match injury episodes occurred in September and the majority of match injury episodes were associated with tackling $(40 \%)$ or with being tackled (24\%). Nine per cent of schoolboy match injury episodes were classified as severe, compared to $13 \%$ for clubs. Sixteen per cent (n = 23) of all schoolboy match injury episodes resulted in missed school attendance compared with $27 \%(n=117)$ of all senior club match injury episodes which involved loss of employment or education. Conclusions-Schoolboy rugby is much safer than senior club rugby and the outcome of injuries that do occur is less disruptive. The relatively high rate of match injury in September might be reduced by a more intensive period of preseason training.

(Br F Sports Med 1996;30:213-217)

Key terms: prevention; rugby football injuries; schoolboys; senior club players

Most surveys on rugby injuries have involved adults $^{1-3}$ or adult and schoolboy presentations to either accident and emergency departments or general practitioners. ${ }^{4-6}$ Fewer studies have involved schoolboys alone and most of these have been carried out in South Africa ${ }^{78}$ or Australasia. ${ }^{9-11}$ The only two British studies were completed more than 15 years ago. One retrospective study ${ }^{12}$ reported injury rates at Rugby school from 1950 to 1979 per 10000 hours played. No information on playing position, competitive level, or prevalence for different injury types was reported. The other study ${ }^{13}$ looked at cervical spine injuries occurring in schoolboys who presented at hospital spinal units from 1971 to 1978 . A further rugby injuries study was completed in Eire in 1980 involving schoolboys, ${ }^{14}$ but it concerned factors which predisposed to injury in the previous year.

In this present survey we provide information on the frequency, nature, site, and outcome of rugby injuries in schoolboys and compare them to injuries occurring in 26 senior rugby clubs. ${ }^{15}$ Baseline information about players and injury data was collected using identical questionnaires. Similar methods were employed for the follow up of the schoolboy and senior rugby club players.

\section{Methods}

Players were eligible if they attended public or private rugby playing schools in Edinburgh or the Borders region of south east Scotland, or if they were a member of a Scottish Rugby Union affiliated rugby club (South of Scotland District) during the 1993-1994 rugby season. All nine rugby playing schools in Edinburgh and all 26 rugby clubs in the South of Scotland agreed to participate. Their injury ascertainment was complete and only their data are presented here. Injury ascertainment for schools in the Borders region was incomplete and has not been used in the analysis. The results of injuries which occurred in the senior rugby clubs have been described elsewhere. ${ }^{15}$

All schoolboys who played rugby at participating Edinburgh secondary schools were asked to complete a questionnaire detailing general personal information, including physical build and their usual rugby playing position. Written permission to examine their medical records if injury subsequently occurred was obtained before the survey began (a parent or guardian was asked to sign the consent form if the boy was under 16 years of age). An adult linkperson was appointed for each school, for example, rugby teachers, school matrons, or school nurses, to record injury details on a standard closed questionnaire and notify the research staff of each 
Table 1 Frequency and distribution of injury episodes occurring in matches

\begin{tabular}{|c|c|c|c|c|c|c|}
\hline & $\begin{array}{l}\text { Age group } \\
\text { (years) }\end{array}$ & $\begin{array}{l}\text { Number of } \\
\text { players }\end{array}$ & $\begin{array}{l}\text { Number of } \\
\text { injured } \\
\text { players }\end{array}$ & $\begin{array}{l}\text { Injury episodes } \\
\text { new }+ \\
\text { (recurrent) }\end{array}$ & $\begin{array}{l}\text { Incidence }(95 \% \text { CI) per } \\
1000 \text { player-seasons }\end{array}$ & $\begin{array}{l}\text { Prevalence }(95 \% \text { CI) per } \\
1000 \text { player-seasons }\end{array}$ \\
\hline Schools & $\begin{array}{l}11 \\
12 \\
13 \\
14 \\
15 \\
16 \\
17-19\end{array}$ & $\begin{array}{l}131 \\
286 \\
345 \\
327 \\
225 \\
222 \\
169\end{array}$ & $\begin{array}{l}2 \\
9 \\
16 \\
20 \\
19 \\
27 \\
33\end{array}$ & $\begin{array}{l}2+(0) \\
12+(1) \\
16+(0) \\
21+(2) \\
20+(0) \\
28+(4) \\
39+(3)\end{array}$ & $\begin{array}{l}15.3(-5.7 \text { to } 36.3) \\
42.0(18.7 \text { to } 65.2) \\
46.4(24.2 \text { to } 68.6) \\
64.2(37.6 \text { to } 90.8) \\
88.9(51.7 \text { to } 126.1) \\
126.1(82.5 \text { to } 170.0) \\
230.8(167.2 \text { to } 294.3)\end{array}$ & $\begin{array}{l}15.3(-5.7 \text { to } 36.3) \\
45.5(21.3 \text { to } 69.6) \\
46.4(24.2 \text { to } 68.6) \\
70.3(42.6 \text { to } 98.1) \\
88.9(51.7 \text { to } 126.1) \\
144.1(97.9 \text { to } 190.3) \\
248.5(183.4 \text { to } 313.7)\end{array}$ \\
\hline Total & & 1705 & 126 & $138+(10)$ & 80.9 (68.0 to 93.9$)$ & $86.8(73.4$ to 100.2$)$ \\
\hline Senior clubs & $\begin{array}{l}<16 \\
16-19 \\
20-24 \\
25-29 \\
30-34 \\
\geq 35\end{array}$ & $\begin{array}{l}204 \\
245 \\
294 \\
243 \\
128 \\
55\end{array}$ & $\begin{array}{l}22 \\
50 \\
100 \\
74 \\
33 \\
11\end{array}$ & $\begin{array}{l}24+(2) \\
62+(10) \\
130+(25) \\
95+(19) \\
36+(14) \\
11+(1)\end{array}$ & $\begin{array}{l}117.6(73.4 \text { to } 161.9) \\
253.1(198.6 \text { to } 307.5) \\
442.2(385.4 \text { to } 498.9) \\
390.9(329.6 \text { to } 452.3) \\
281.3(203.4 \text { to } 359.1) \\
200.0(94.3 \text { to } 305.7)\end{array}$ & $\begin{array}{l}127.5(81.7 \text { to } 173.2) \\
293.9(236.8 \text { to } 350.9) \\
572.2(470.1 \text { to } 584.3) \\
469.1(406.4 \text { to } 531.9) \\
390.6(306.1 \text { to } 475.1) \\
218.2(109.0 \text { to } 327.3)\end{array}$ \\
\hline Total & & 1169 & 290 & $358+(71)$ & $306.2(279.8$ to 332.7$)$ & 367.0 (339.4 to 394.6$)$ \\
\hline
\end{tabular}

CI, confidence interval.

injury episode. The outcome of an injury was obtained by contacting the player or his parents directly, as well as from hospital and general practitioner records. Age was defined as age last birthday on 31 August 1993. A rugby injury was defined as an injury sustained on the field during a competitive match, during a practice game, or during other training activity directly associated with rugby football, which prevented the player from training or playing rugby football from the time of the injury or from the end of the match or practice session in which the injury was sustained. The International classification of diseases (9th revision) was used to code injuries. In the case of multiple injuries, the decision on which injury was primarily responsible for incapacity was a matter of clinical judgement. Injury severity was classified by the number of days a player missed from training or playing in matches: transient, less than seven days; mild, 7-28 days; moderate, 29-84 days; and severe, more than 84 days.

Since some of the older first year pupils had their 11th birthday during the previous rugby season, it was decided to only record injuries for those who would be 12 years old in the 1993-1994 rugby playing season (up to 30 April 1994); 1705 (98\%) of the 1736 rugby players in the nine Edinburgh schools and $1169(96 \%)$ of the 1216 senior rugby club players returned the census form.

Durations of injury and time off work or education were calculated as the difference between the date of injury and the date of return to play or work/education. For schoolboys the actual number of days off school work was also calculated.

Logistic regression assessed the interaction between group (club or school) and age; if no interaction was present then Mantel-Haenszel weighted odds ratio was used to determine the risk of injury in club players compared to schoolboys over the individual age years. A $\chi^{2}$ test for trend was used to ascertain if there was a trend in the proportions of injured players with age. The probability of a player losing a particular number of playing or training days through injury was determined by KaplanMeier estimates, and the log-rank test was used to compare the injury durations between clubs and schools, stratifying by age.

\section{Results}

FREQUENCY AND DISTRIBUTION OF INJURIES

There were 186 rugby injury episodes resulting in 210 separate injuries recorded for participating Edinburgh schools, with 154 (9\%) of the 1705 registered players being injured during the 1993-1994 rugby season. Sixteen players were injured twice, five players were injured three times and two players were injured four times. One hundred and forty eight $(80 \%)$ of these injury episodes (involving 126 schoolboys) were recorded while playing in a match. The incidence and prevalence per 1000 playerseasons for injury episodes occurring in school and senior rugby club matches is presented in table 1 . The player incidence of match injury for those aged 11-19 years was 73.9 (95\% confidence interval 61.5 to 86.3$)$ and 160.4 (126.4 to 194.3 ) per 1000 player-seasons for schools and clubs respectively. Interaction between group and age was observed (logistic regression, $P=0.004$ ) in injury rates for those aged 11-19 years. Younger rugby club players (aged 11-13 years) had a higher risk of injury than school players of the same age (odds ratio $3.27,95 \%$ confidence interval 1.54 to 6.81 ) as did players aged 14-16 years, although the risk was lower than that of the youngest boys (odds ratio $2.15 ; 1.35$ to 3.39 ). Players aged $17-19$ years had no increased risk (odds ratio 1.22; 0.62 to 2.40 ). Schoolboys had fewer recurrent match injuries $(7 \%)$ compared to club players aged $11-19$ years $(12 \%)$. A significant trend in the match injury rate for schoolboys was observed over the nine individual years of age $\left(\chi^{2}\right.$ test for trend: $\chi^{2}=55.0, P<0.0001$ ), with the rate of injury rising from 15.3 injuries per 1000 player-seasons in 11 year olds to 248.5 for those players aged 17-19 years.

\section{NATURE AND SITE OF INIURY}

Senior club players had a higher match injury prevalence for all types of injury compared to school players (table 2), with a higher proportionate prevalence in clubs for dislocations, strains and sprains to the hip and thigh, fractures to the head, neck, and face, back 
Table 2 Site and nature of primary injuries sustained in matches

\begin{tabular}{|c|c|c|c|c|}
\hline \multirow[b]{2}{*}{ Site and nature of primary injury } & \multicolumn{2}{|l|}{ Schools } & \multicolumn{2}{|l|}{ Clubs } \\
\hline & $\begin{array}{l}\text { Number of } \\
\text { injuriest }\end{array}$ & $\begin{array}{l}\text { Prevalence }(95 \% \text { CI) per } \\
1000 \text { player-seasons }\end{array}$ & $\begin{array}{l}\text { Number of } \\
\text { injuriest }\end{array}$ & $\begin{array}{l}\text { Prevalence }(95 \% \mathrm{CI}) \text { per } \\
1000 \text { player-seasons }\end{array}$ \\
\hline $\begin{array}{l}\text { Head, neck, and face } \\
\text { Concussion } \\
\text { Fracture } \\
\text { Lacerations and contusions }\end{array}$ & $\begin{array}{l}16+2=18 \\
1+0=1 \\
11+0=11\end{array}$ & $\begin{array}{l}10.6(5.7 \text { to } 15.4) \\
0.6(-0.6 \text { to } 1.7) \\
6.5(2.7 \text { to } 10.3)\end{array}$ & $\begin{array}{l}19+1=20 \\
10+0=10 \\
37+0=37\end{array}$ & $\begin{array}{l}17.1(9.7 \text { to } 24.5) \\
8.6(3.3 \text { to } 13.8) \\
31.7(21.6 \text { to } 41.7)\end{array}$ \\
\hline $\begin{array}{l}\text { Shoulder } \\
\text { Dislocations, strains, and sprains }\end{array}$ & $13+1=14$ & $8.2(3.9$ to 12.5$)$ & $31+17=48$ & $41.1(29.7$ to 52.4$)$ \\
\hline $\begin{array}{l}\text { Upper limb } \\
\text { Fracture } \\
\text { Dislocations, strains, and sprains } \\
\text { Lacerations and contusions }\end{array}$ & $\begin{array}{l}28+0=28 \\
4+0=4 \\
6+0=6\end{array}$ & $\begin{array}{l}16.4(10.4 \text { to } 22.5) \\
2.3(0.0 \text { to } 4.6) \\
3.5(0.7 \text { to } 6.3)\end{array}$ & $\begin{array}{l}22+0=22 \\
13+1=14 \\
9+0=9\end{array}$ & $\begin{array}{l}18.8(11.0 \text { to } 26.6) \\
12.0(5.7 \text { to } 18.2) \\
7.7(2.7 \text { to } 12.7)\end{array}$ \\
\hline $\begin{array}{l}\text { Trunk } \\
\text { Back strains and sprains } \\
\text { Lacerations and contusions }\end{array}$ & $\begin{array}{l}7+0=7 \\
5+0=5\end{array}$ & $\begin{array}{l}4.1(1.1 \text { to } 7.1) \\
2.9(0.4 \text { to } 5.5)\end{array}$ & $\begin{array}{l}35+10=45 \\
17+0=17\end{array}$ & $\begin{array}{l}38.5(27.5 \text { to } 49.5) \\
14.5(7.7 \text { to } 21.4)\end{array}$ \\
\hline $\begin{array}{l}\text { Lowver } \lim b \\
\text { Fractures } \\
\text { Dislocations, strains, and sprains: }\end{array}$ & $5+0=5$ & $2.9(0.4$ to 5.5$)$ & $10+1=11$ & 9.4 (3.9 to 14.9$)$ \\
\hline $\begin{array}{l}\text { Hip and thigh } \\
\text { Knee } \\
\text { Ankle and foot } \\
\text { Lacerations and contusions }\end{array}$ & $\begin{array}{l}3+1=4 \\
13+1=14 \\
11+1=12 \\
10+1=11\end{array}$ & $\begin{array}{l}2.3(0.0 \text { to } 4.6) \\
8.2(3.9 \text { to } 12.5) \\
7.0(3.1 \text { to } 11.0) \\
6.5(2.7 \text { to } 10.3)\end{array}$ & $\begin{array}{l}31+9=40 \\
56+16=72 \\
21+8=29 \\
23+1=24\end{array}$ & $\begin{array}{l}34.2(23.8 \text { to } 44.6) \\
61.6(47.8 \text { to } 75.4) \\
24.8(15.9 \text { to } 33.7) \\
20.5(12.4 \text { to } 28.7)\end{array}$ \\
\hline Other injuries & $5+3=8$ & $4.7(1.4$ to 7.9$)$ & $24+7=31$ & 26.5 (17.3 to 35.7$)$ \\
\hline All injuries & $138+10=148$ & $86.8(73.4$ to 100.2$)$ & $358+71=429$ & $367.0(339.4$ to 394.6$)$ \\
\hline
\end{tabular}

†New injuries + recurrent injuries $=$ total injuries.

CI, confidence interval.

strains and sprains, and also dislocations, strains, and sprains to the knee. The reverse was true for upper limb fractures and concussion; these injuries had the highest prevalence in schoolboys, but only ranked ninth and tenth in frequency for club injuries. Fractures of the clavicle and of the hand bones were the most common upper limb fractures, occurring in matches for schoolboys $(n=11$ and $n=13$ respectively) and senior club players ( $n=5$ and $\mathrm{n}=15$ respectively). The mean age of players reporting concussion in matches or training was 14.9 years (SEM 0.29) and 18.3 years (SEM 0.95) for school and club players respectively. No spinal injuries were recorded in 1705 school and 1169 club player-seasons.

\section{INJURY ASSOCIATION}

There were more schoolboy injury episodes at the beginning of the season, with one third (63) of all injury episodes (48 from matches) occurring in the month of September. The majority of schoolboy match injury episodes occurred in the tackle; $59(40 \%)$ were associated with tackling and a further $35(24 \%)$ with being tackled. Rucking was involved in 19 (13\%) of the schoolboy match injury episodes, including $29 \%$ of back strains and sprains and $40 \%$ of trunk lacerations and contusions. Very few schoolboy match injury episodes were caused in the scrum (3), maul (3), lineout (2), gathering the ball (8), and away from the ball (6). The remaining 13 injury episodes occurred in other circumstances. For senior rugby clubs, a higher proportion of match injury episodes occurred because of the scrum $(8 \%)$ and ruck (15\%), but tackling $(21 \%)$ and being tackled $(28 \%)$ still accounted for the highest proportions of injury episodes. Match injury episodes were evenly distributed between forwards and backs for school players.
However, more shoulder dislocations, strains, and sprains occurred in forwards $(71 \%)$ than in backs $(29 \%)$, and all five lower limb fractures occurred in backs. Injuries were also evenly distributed between forwards and backs at senior club level, except that forwards had more head, neck, and face fractures $(70 \%)$, trunk strains and sprains (73\%), and truck lacerations and contusions ( $76 \%)$, whereas backs had more upper limb dislocations, strains, and sprains $(71 \%)$.

\section{OUTCOME}

One in every five injured senior club players completed the match and one in eight completed the training session in which they were injured, whereas only $5 \%$ of injured schoolboys completed the match and none completed the training session in which they were injured. Those schoolboys completing the match had minor injuries, whereas the injuries of the senior club players who finished the match or training session were more serious: $17(16 \%)$ of them went on to miss work or education as a result of their injury. Of the 20 schoolboys recorded as being concussed in training or a match, $40 \%$ (8) played again within 21 days and two of these boys experienced further concussion in their next match. Both were playing in school competitive matches, 6 and 15 days later.

More senior club match injury episodes were classified as severe (13\%) than school match injury episodes (9\%). Ten per cent of injured senior club players missed 133 or more rugby playing days (19 weeks) through match injury compared to $4 \%$ of injured schoolboys. However, there was no significant difference in the duration of match injury between club and school players (log-rank test, stratified by age, $P=0.45$ ). 
Twenty three schoolboy match injury episodes $(16 \%)$ and 12 training injury episodes $(32 \%)$ resulted in periods of school absence. A total of 117 injury episodes from club matches $(27 \%)$ resulted in time off school or work for 111 different players and 24 injury episodes from training (29\%) for 23 individual players. For those missing work or education following a match injury, the mean duration of absence (from the date of injury to the date of return) was 3.6 (SEM 0.5) days for schoolboys and 18.0 (2.3) days for club players. The mean number of days actually off school was also calculated; this was 2.2 (0.3) days, with four out of every five pupils missing only one or two days. The mean duration of absence for those missing work or education was much higher for all types of injury for club players, except for concussion, where the mean absence was 3.5 days for both club and school players. Fractures resulted in the most time off for both schoolboys and senior club players, the highest for lower limb fractures (means 5.5 days for schoolboys and 38.3 days for senior club players). Although there was a considerable difference between schoolboys and club players in the mean number of days absent from education or work, the types of fractures which occurred were similar in both groups.

\section{Discussion}

This is the first comparison of schoolboy and senior club rugby in Britain that details the frequency, nature, type, and duration of injury. There are less 17 and 18 year olds in this survey than would be expected for these schools, because only pupils who played rugby participated in this survey. Older pupils will probably have more choice in the sport they play and may decide not to play rugby. Thus the cohort may not be representative of older schoolboys.

One third of all injury episodes occurred in September, confirming the work of others who found that injury rates are higher at the beginning of the season. ${ }^{78}$ This could be due to lower levels of fitness at the start of the season for most players and as a consequence a higher proportion of players could be injured. This might be reduced by a more intensive period of preseason training. Tackling is another area where it may be possible to reduce injury rates (since two thirds of match injury episodes occurred while tackling and being tackled).

The prevalence of rugby injuries increases with age in schoolboys. ${ }^{710}$ The smaller build and strength of younger boys may result in fewer injuries in collisions with each other. Also as rugby may be a compulsory part of the school curriculum for younger players, their enthusiasm and competitiveness may be less than among older pupils, who may choose rugby in preference to other sports. The more dedicated players (senior club players 11-16 years of age) have a greater risk of injury than schoolboys in the same age group. Young club players of comparable age also have a higher rate of recurrent injuries. Although there was no significant difference between school and club players in the number of rugby playing days missed, more club players had long dura- tions of injury. Senior club players will generally be more committed to rugby than schoolboys and may return to play earlier following an injury of a similar level of severity. This commitment is reflected in the proportions of senior club players completing the game or training session in which they were injured. Thus the severity of injury may be more marked between club and school players than the duration of injury suggests.

For each injury type, the time off school for pupils is much lower than the time off work for senior club players. This could be related to the severity of the injuries. However, the mobility and physical effort of attending school may be less than that required for most jobs and could have been an influence on the amount of time missed.

It is not clear why schoolboys have such a high rate of upper limb fractures (ICD 810.0, $\mathrm{n}$ $=11 ; 813.0, \mathrm{n}=1 ; 813.4, \mathrm{n}=3 ; \mathrm{n}=814.0, \mathrm{n}=$ $2 ; n=815.0, n=4 ;$ and $816.0, n=7)$. These sites account for almost one fifth of all match injury episodes. It may be that schoolboys are more inexperienced in tackling than club players. A relatively high rate of concussion (one eighth of all match injury episodes) was recorded in schoolboy rugby, which agrees with the results of other studies. $^{78}$ One explanation may be that any knock to the head was regarded as concussion by the school linkperson and was not related to the accepted definitions of minor head injury. ${ }^{16}$ The rugby authorities recommend that players who experience concussion should not play again for at least 21 consecutive days. ${ }^{1718}$ However, schoolboys were found to be playing again within this time limit, although the numbers involved were small. Rugby coaches and others need to be reminded that once a player has had concussion, the chance that it will occur again may be greater than for a player who has never sustained concussion ${ }^{19}$ and that the effects of repeated minor head injuries may be cumulative. ${ }^{2021}$ It was interesting to note that no spinal injuries occurred in the 1705 schoolboy players and 1169 rugby club players. Despite this type of injury being an extremely rare event, it is the rugby injury that has been the focus of much media attention. ${ }^{22-24}$

In conclusion, school rugby is much safer than rugby played by senior clubs. Those schoolboy injuries that do occur are not so serious and most players are fit to play again within a month. Very little time was lost from school work as a result of injuries sustained in school rugby.

We thank George Murray, district secretary for the South of Scotland; the presidents of participating clubs; linkpersons of participating clubs and schools; Donald Macleod, honorary medical advisor, SRU for comment on an earlier draft of the paper; Gregor Nicholson, administrative secretary, SRU; Sue Hutton, our survey coordinator and the chartered physiotherapists of the Fitness Assessment and Sports Injuries Centre, University of Edinburgh Department of Physical Education; Lyn Chalmers for computing support; Robin Prescott for statistical advice; Anne Simmons and Caroline Adams for secretarial
services.

$1 O^{\prime}$ Brien C. Retrospective survey of rugby injuries in the Leinster province of Ireland 1987-1989. Br $\mathcal{F}$ Sports Med 1992;26:243-4.

2 Myers PT. Injuries presenting from Rugby Union football. Med $\mathcal{F}$ Aust 1980;2:17-20. 
3 Davies JE, Gibson T. Injuries in Rugby Union football. $B M 7$ 1978;ii: $1759-61$

4 Dixon G. Morbidity of Rugby Union injuries in New Zealand. NZ Sports Med 1993;2:18-20.

5 McQuillan R. A survey of rugby iniuries attending an accident and emergency department. Irish Med $f 1992 ; 85: 72-3$.

6 Roy SP. The nature and frequency of Rugby Union injuries. A pilot study of 300 injuries at Sellenbosch. $S$ Afr Med $\mathcal{J}$ 1974;48:2321-7.

7 Roux CE, Goedeke R, Visser GR, Van Zyl WA, Noakes TD The epidemiology of schoolboy rugby injuries. $S$ Afr Med 1987;71:307-13.

8 Nathan $M$, Goedeke R, Noakes TD. The incidence and nature of rugby injuries experienced at one school during the 1982 rugby season. $S$ Afr Med $\mathcal{F} 1983 ; 64: 132-7$.

9 Dalley DR, Laing DR, McCartin PJ. Injuries in rugby football, Christchurch, 1989. NZ $₹$ Sports Med 1991;20:2-5.

10 Davidson RM. Schoolboy rugby injuries, 1969-1986. Med $f$ Aust 1987;147:119-20.

11 Sugerman S. Injuries in an Australian schools rugby union season. A ust ₹ Sports Med Exerc Sci 1983;15:5-14.

2 Sparks JP. Half a million hours of rugby football. The injuries. Br $\mathcal{F}$ Sports Med 1981;15:30-2.

13 Hoskins T. Rugby injuries to the cervical spine in English schoolboys. Practice of Medicine 1979;223:265-366.

14 Watson AWS. Factors predisposing to sports injury in school boy rugby players. $\mathcal{f}$ Sports Med $1981 ; 21: 417-22$.
15 Garraway M, Macleod D. Epidemiology of rugby football injuries. Lancet 1995;345:1485-7.

16 Jane JA. Definitions. In: Hoff TJ, Anderson TE, Cole TM eds. Mild to moderate head injury. Oxford: Blackwel Scientific Publications, 1989.

17 Scottish Rugby Union. Coaching and medical manual. 1995/ 96 , page 22 , section 1 .

18 IRFB handbook, page 106, resolution 5.5. April 1995.

19 Gerberich SG, Priest JD, Boen JR, Straub CP, Maxwell RE. Concussion incidences and severity in secondary school varsity football players. Am $\mathcal{f}$ Public Health 1983;73: 1370-5.

20 Gronwell D, Wrightson P. Cumulative effects of concussion. Lancet 1975;ii:995-7.

21 Gronwell D, Wrightson P. Memory and information processing capacity after closed head injury. $₹$ Neurol Neurosurg Psychiatry 1981;44:889-95.

22 Kew T, Noakes TD, Kettles AN, Goedeke RE, Newton DA Scher AT. A retrospective study of spinal cord injuries in Cape Province rugby players, 1963-1989. Incidence, mechanisms and prevention. $S$ Afr Med $f$ 1991;80: 127-33.

23 Scher AT. Spinal cord concussion in rugby players. $A m \mathcal{F}$ Sports Med 1991;19:485-8.

24 Silver JR. Injuries of the spine sustained during rugby. $\mathrm{Br} f$ Sports Med 1992;26:253-8. 